\title{
Nuevos formatos publicitarios televisivos y perspectiva de género
}

\author{
Estela BERNAD MONFERRER \\ Universitat Jaume I, Castellón \\ bernad@uji.es
}

Recibido: 24/07/2012

Aceptado: 31/10/2012

\begin{abstract}
Resumen
La emergencia de las nuevas tecnologías de la comunicación ha comportado una progresiva evolución de la televisión, que ha supuesto un cambio radical en sus formas de comunicar. No obstante, pese al avance y modernización de los nuevos formatos publicitarios televisivos, detectamos que el tratamiento de los contenidos continúa apoyándose en temáticas desequilibradas y manidas en cuanto al tratamiento del género. Con este trabajo, se pretende incardinar una visión igualitaria en la lectura de estos formatos televisivos que permita detectar y erradicar aquellos comportamientos que continúan arrastrando los vicios identificados en conductas discriminatorias y sexistas propias de lecturas patriarcales y andróginas, detectándose que aunque las nuevas tecnologías de la comunicación han comportado un cambio radical en la forma de comunicar, queda todavía un importante camino hasta alcanzar la igualdad efectiva de gé-
\end{abstract} nero.

Palabras clave: Formatos publicitarios televisivos, perspectiva de género, alfabetización mediatica, publicidad interactiva, estereotipo.

\section{New formats for television advertising and gender perspective}

\begin{abstract}
:
The emergence of new communication technologies has led to a gradual evolution of television, which has meant a radical change in their way of communicating. However, despite the progress and modernization of new television advertising formats, it is detected that treatment of content continues to rely on hackneyed themes and unbalanced in the gender treatment. The aim of this work is to incardinar egalitarian vision in reading these television formats to detect and eradicate those behaviors that continue dragging the defects identified in discriminatory and sexist behavior own of patriarchal and androgynous readings, detecting that although new technologies communication have brought about a radical change in the way we communicate, there is still an important way to achieve effective gender equality.
\end{abstract}

Keywords: Television advertising formats, gender, media literacy, interactive advertising, stereotype.

\section{Referencia normalizada}

BERNAD MONFERRER, Estela (2012): "Nuevos formatos publicitarios televisivos y perspectiva de género". Estudios sobre el mensaje periodístico. Vol. 18, núm. especial octubre, págs.: 151-159. Madrid, Servicio de Publicaciones de la Universidad Complutense.

Sumario: 1. Introducción.2. Metodología. 3. Desarrollo; 3.1. Otro nuevo tipo de publicidad: "La publicidad interactiva"; 3.2. El efecto culturizador de los medios de comunicación y la publicidad y su importancia en la perspectiva de género. 3.3. Publicidad y estereotipos de género. 4. Conclusión. 5. Referencias bibliográficas

\section{Introduction}

La alfabetización toma muchas formas y una de ellas es a través de los medios de comunicación y en concreto de la televisión. Tras las conclusiones de la Plataforma de Acción de Beijing, la alfabetización mediática se ha venido trabajando respecto a la relación de las mujeres con los medios y las posibilidades de utilización de los mis- 
mos así como los obstáculos para conseguir evitar la brecha digital y las acciones a desplegar para poder educar a través de los medios en clave de igualdad.

Así, hemos de tener en cuenta que la cultura esta constituida por multitud de elementos visuales y sonoros, que genera distintos contenidos con un lenguaje mucho más atractivo, dinámico y estimulante por que en la actualidad ya no basta con saber leer y escribir correctamente. Los medios de comunicación, por este motivo, juegan un importante papel para solucionar las nuevas formas de analfabetismo, ya que a través de ellos puede enseñarse a la gente cómo utilizar las tecnologías de la información y la comunicación. También pueden llegar a reforzar la maduración del público como ciudadanía responsable y educar desde un punto de vista transversal, para comprender el mundo que les rodea y saber actuar en él.

Por otro lado, la emergencia de las nuevas tecnologías de la comunicación ha comportado una progresiva y vertiginosa evolución de la televisión, que ha supuesto un cambio radical en sus formas de comunicar. Este hecho ha originado la aparición de nuevas y distintas dimensiones, que involucran a la audiencia antaño pasiva, en el proceso comunicativo, haciéndola participe del mismo, desde el momento que se le invita a interactuar con el medio, teniendo en cuenta su participación y opinión en muchos casos. En este sentido, parte de la comunicación publicitaria que se emite mediante este soporte ha dejado de ser unidireccional y jerárquica para pasar a ser bidireccional y participativa.

No obstante, pese al avance y modernización de los nuevos formatos publicitarios televisivos, detectamos que el tratamiento de los contenidos continúa apoyándose en temáticas desequilibradas y manidas en cuanto al tratamiento del género. Se sigue persistiendo en el empleo de estereotipos discriminatorios de género, y utilizando de manera gratuita el cuerpo femenino como reclamo y objeto sexual, asistiéndose a un periodo caracterizado por una autentica cosificación de los cuerpos, convirtiéndose en un producto más de consumo.

Con este trabajo, se pretende incardinar una visión igualitaria en la lectura de los nuevos formatos televisivos que permita detectar y erradicar aquellos comportamientos que continúan arrastrando los vicios identificados en conductas discriminatorias y sexistas propias de lecturas patriarcales y andróginas, detectándose que aunque las nuevas tecnologías de la comunicación han comportado un cambio radical en la forma de comunicar provocando distintas y nuevas dimensiones y democratizando su uso, queda todavía un importante camino por realizar para conseguir que la igualdad de género que promulga nuestro derecho, sea real y efectiva.

\section{Metodología}

Internet, ha sido un instrumento fundamental para cambiar la mentalidad del espectador y modificar sus hábitos y costumbres en cuanto al consumo televisivo. Y en concreto para cambiar los formatos publicitarios que se anuncian a través de la televisión. Esto hace que aparezcan un sin fin de productos novedosos y avanzados de publicidad interactiva en el mercado televisivo (Spot interactivo, patrocinio Interactivo a programas, guía de programación o EPG, servicios de Teletexto Digital, Walled Garden, video bajo demanda (VOD) etc) con desarrollos de contenidos variados, muchas veces coincidentes con los anuncios televisivos tradicionales y otras, diferentes. 
Para la realización de este trabajo, se han estudiado muchos de los contenidos que recogen estos nuevos formatos publicitarios, examinándolos desde la perspectiva de género, encontrando que en muchos de los casos, continúan apoyándose en temáticas desequilibradas y manidas, pues siguen la línea de la publicidad tradicional. En ésta, todavía persisten comportamientos machistas que ayudan a difundir un tratamiento discriminatorio de la imagen de la mujer, mostrando representaciones violentas y degradantes e incluso descripciones estereotipadas, tal como se recoge en el informe del Observatorio de la Publicidad sexista $2000^{1}$.

De ahí nuestra preocupación por el tratamiento de género en la publicidad a través de las nuevas plataformas digitales, pues su difusión más rápida y global ayudan a difundir modelos estereotipados y degradantes en el tratamiento de la mujer.

\section{Desarrollo}

\subsection{Otro nuevo tipo de publicidad: "La publicidad interactiva"}

Internet facilita la posibilidad de poder visionar los programas en cualquier momento, iniciándose un nuevo consumo televisivo que desarrolla contenidos en foros y comunidades de fans, reforzando la fidelización de los públicos y popularizando los contenidos emitidos de forma universal.

De esta manera las grandes cadenas televisivas al observar que la forma tradicional de obtener ingresos a través de la publicidad y la venta de derechos de las emisiones corría peligro, han apostado por otros formatos publicitarios, percibiendo que Internet les permite desarrollar nuevas estrategias basándose en el consumo plataforma. Mediante esta herramienta, se deben reforzar los lazos de unión con los públicos a través de las nuevas redes de comunicación. Así, Internet ofrece además de los contenidos íntegros, avances, juegos, e información sobre programas y sus personajes y en ellos también integra la publicidad.

Por este motivo, el público consumidor y usuario, hoy más que nunca se ha convertido en el centro de interés para las empresas. Ya no se trata de acercarlo a la marca, sino de aproximar ésta al mismo, interactuando con él, incluso, "intimando a través de una relación personalizada, a medida, pues se incorporará a los mensajes publicitarios que se le emitan su realidad para acercar la marca dentro del universo de consumo de éste, dejando de lado su tratamiento como cliente para pasar a convertirse en "público amigo".

En este contexto se observa como la publicidad tradicional ha sufrido un gran cambio que no cesa en su avance, ante todo por la aparición de la digitalización, el surgimiento de Internet y la reciente y avanzada aparición de las Redes Sociales. La publicidad convencional a través del spot permite llegar al público objetivo mediante las variables de planificación de medios como son la cobertura y la frecuencia. Sin embargo, el punto débil es el objetivo de llegar a contactar cualitativamente con el público. Esta debilidad es superada por los nuevos formatos publicitarios. Éstos a través de ideas novedosas gestionadas correctamente en la World Wide Web canalizan el flujo

${ }^{1}$ OBSERVATORIO DE LA IMAGEN DE LAS MUJERES, Instituto de la Mujer, Informes 2000, pp 3. 
óptimo de comunicación en internet, para poder situar la marca de modo voluntario en los comentarios del usuario/a. (Vinyals, Echazarreta y Martín Casado, 2011).

Hemos de señalar que este fenómeno de la publicidad en la red se ha ido introduciendo en los hogares españoles, en la medida que Internet ha ido ganando poco a poco su espacio, erradicando de las preferencias familiares, a otros medios de comunicación tradicionalmente líderes ${ }^{2}$. Así, como indica Caldevilla (2010), se acude al ordenador para prácticamente todo (consultas sobre productos, compras, entretenimiento, comunicación...) dejando atrás otros medios de comunicación y formas tradicionales de relaciones sociales.

Esta circunstancia ha venido propiciada por varios factores, siendo uno de ellos el hecho de que internet se ofrece como plataforma para diversificar la oferta televisiva teniendo la ventaja de poder ser visionado al gusto y horario que la persona consumidora quiera o pueda disponer. Películas o series emitidas en horarios intempestivos pueden, de esta forma, ser contemplados en otros momentos, garantizando un éxito que de otra manera no tendrían. Por este motivo, las cadenas públicas y privadas apuestan por ofrecer programación a través de sus páginas en Internet, suponiendo un nuevo espacio donde ofertar publicidad".

La entrada de las nuevas tecnologías de la comunicación ha supuesto un cambio en el escenario tradicional, con nuevos formatos que reúnen elementos que garantizan su éxito como la utilidad, la gratuidad y la facilidad. Es aquí donde aparece la publicidad en los medios sociales, es decir, el social media marketing. La publicidad en blogs, comunidades y redes sociales que permite interactuar y saber lo que piensan y sienten los usuarios con relación al producto promocionado. El intercambio de comunicación entre anunciante y cliente es real y no impuesto y genera acercamiento, simpatía y dinamismo.

Con este cambio de modelo la publicidad en los social media se plantea los siguientes objetivos: atraer, seducir, entretener, apetecer y a la vez que merezca la pena ser visto, que sea relevante, interesante y actual, es decir, algo digno de compartir. Apoyados en esta idea nacen nuevos modelos publicitarios como los advergames que son juegos interactivos con publicidad, y que poseen altas posibilidades de éxito al estar dirigidos a un público que pasa gran parte de su tiempo en la web.

Ante este nuevo reto, la publicidad interactiva proporciona una comunicación más profunda entre el/la anunciante y su target, pues el usuario/a ha elegido esa opción de forma voluntaria, cuando tiene un interés por el producto o servicio anunciado. De esta manera, además de ofrecer la información sobre su producto, el/la anunciante obtendrá un retorno inmediato, según las fórmulas que haya diseñado para ello (muestras gratuitas, promociones, catálogos...) que le permitirán obtener los datos de las personas que hayan participado en la respuesta del anuncio interactivo.

2 En el estudio de Mediascope 2008 realizado por la European Interactive Advertising Association, por lo que respecta a España, se puede comprobar como en 2008 las horas semanales dedicadas a la televisión son un $11,7 \%$ mientras que las dedicadas a Internet son un 12,1\%. http://slidesha.re/x2gXXP. 
Por otro lado, la digitalización del sistema televisivo, ha aumentado las posibilidades interactivas de la televisión haciendo que el usuario/a desempeñe un papel más activo en el proceso de comunicación viendo incrementadas sus posibilidades de participación (Aymerich, 2007) pues supone un complemento de valor añadido para la televisión tradicional y proporcionando una gama amplísima de recursos para emplazar su publicidad, pues puede visionarse a través de un consumo lineal o de forma interactiva, a partir de acceder a la aplicación interactiva diseñada específicamente para esta finalidad.

\subsection{El efecto culturizador de los medios de comunicación y la publicidad y su importancia en la perspectiva de género.}

Los medios de comunicación han expandido a todos los públicos los modelos culturales que se ofrecen a través de la publicidad. En el tema de género, su importancia reside, por su consideración práctica y política, en su creciente capacidad de influir en la construcción de identidades de género". Porque el género es una construcción cultural. Es a partir del dimorfismo de nuestra especie de donde surge la distinción del sexo biológico de los seres humanos. Pero, en el caso del género, comporta algo más ya que, conlleva una construcción social que perfila determinados caracteres segregando a las personas en función del sexo biológico. La educación y el modelo cultural de las sociedades van a incidir de manera fundamental en esta construcción social y en erigir estereotipos de género muy difíciles de deconstruir.

En este universo, los medios de comunicación, debido a su gran alcance, son instrumentos poderosos de transmisión de mensajes, que si son incorrectos se convierten en plataformas ( $\mathrm{y}$ a veces en modelos a seguir) para expandir situaciones discriminatorias entre los dos sexos.

Así, la publicidad con tintes sexistas y discriminatorios ayuda a consolidar estereotipos de género que en la actualidad, se encuentran culturalmente superados pero que influyen en aquellos colectivos sociales que todavía son inmaduros o sin formación en cuanto a la cultura igualitaria. De esta manera, aquella publicidad que manipula, invisibiliza, y tergiversa el rol femenino en la sociedad, maltrata la imagen de las mujeres consolidando estereotipos que perjudican gravemente no sólo a las mujeres, sino a la sociedad en general, puesto que tener una sociedad igualitaria es signo de tener una sociedad más justa tanto para mujeres como para hombres, y estas prácticas publicitarias y el efecto cultural y social que conlleva no hacen más que dificultar la consecución de la igualdad.

Cuando hablamos de estereotipos de género, nos estamos refiriendo a aquel conjunto de ideas simples, previas e irracionales que se atribuyen a las personas en función de su adscripción sexual, prescribiendo características definitorias sobre su manera de ser -su identidad- y de comportarse -su rol social-, de acuerdo a la prescripción de género, como mecanismo activador de la ideología patriarcal (Bernad, 2010). Este concepto se plasma en situaciones que se extienden en los medios como la cosificación y la reducción de la imagen de la mujer a objeto sexual o perfecta ama de casa. Al estereotipo se le relaciona con la violencia social, pues también consiste en "atribuir un menor valor a la posición social de las mujeres a través de las accio- 
nes que desvalorizan su imagen, la estereotipan condicionando su posición social o les niegan la identidad y el valor personal".

\subsection{Publicidad y estereotipos de género}

Cobo (1995) señala que «el género es una construcción cultural que se ha plasmado históricamente en forma de dominación masculina y sujeción femenina. Esta jerarquización sexual se ha materializado en sistemas sociales y políticos patriarcales». Apoyándonos en esta definición, destacaríamos que esta construcción cultural se ha ido forjando a lo largo de la historia, entorno a una serie de componentes de género: el rol, o componente sociológico; la identidad sexuada, o componente psicológico, y el estatus o componente político, que han venido reproduciendo elementos funcionales como los estereotipos de género, que determinan la reproducción social de la desigualdad entre ambos géneros. Por este motivo, el sistema de representación simbólica que recrea la publicidad, se vale en muchos casos de estas situaciones en su afán de promover el consumo, pues sus mensajes constituyen un marco de referencia fundamental donde surgen modelos y valores a imitar. En no pocas ocasiones los anunciantes adoptan en el mercado una actitud agresiva en su intento de atraer la demanda hacia sí, pretendiendo modificar o consolidar la elección de las ofertas por parte de los consumidores. Sales (2010), pone como ejemplo, el que una gran parte de las mujeres (sin diferencias) tengan unas relaciones menos libres y fáciles con la comida, mientras que el hombre si puede mostrar su apetito.

La publicidad utiliza los estereotipos como formas de simplificar la realidad por lo que acaba produciendo una visión estereotipada del mundo. Las mujeres siguen apareciendo como dependientes, cálidas, sensibles, pacíficas, sumisas, poco autónomas. Los hombres son activos, fuertes, decididos, independientes, responsables, violentos... Los hombres son los que toman las decisiones, actúan, piensan, mientras que las mujeres son la recompensa a su esfuerzo. Aunque muchos de estos estereotipos están cambiando, todavía confluyen en los medios ayudando a conformar el imaginario femenino. La tendencia actual es apostar por líneas mucho más actuales y adaptadas al nuevo entorno de la mujer: todo lo que aplique a su practicidad, capacidad resolutiva $\mathrm{y}$, sobre todo, al individualismo.

A pesar de estas últimas investigaciones, se siguen vinculando a las féminas el "culto de la esbeltez" y la belleza, y la publicidad de productos alimenticios, vinculados al ámbito doméstico, ámbito privado y por tanto esfera tradicionalmente reconocida de actuación de la mujer, según la cultura patriarcal, dejando el ámbito público y productos como seguros, finanzas o coches de alta gama, como esfera de actuación del varón. En este sentido, la publicidad también utiliza el cuerpo de la mujer para anunciar productos destinados al varón, trascendiendo entonces al ámbito público, pero la mayoría de las veces con carácter captatorio ${ }^{3}$.

3 Datos obtenidos del Proyecto de la Universidad de Zaragoza 2002 dirigido por María Elosegui y plasmado n el video "Evolución de los roles de la mujer a través de la publicidad". UZ 2002 y del Observatorio de la Pubelicidad del Instituto de la Mujer. 
Hoy en día, a través de la publicidad se puede transmitir una serie de efectos sociales y concretamente culturales que puede influir a que la audiencia conforme una imagen colectiva de la mujer. Por eso, es fundamental que las imágenes que se difunden a través de la publicidad sean lo más correctas y no discriminatorias posible, aunque la realidad a través de las denuncias a los distintos observatorios de la imagen de las mujeres nos demuestra que no obstante el principio de igualdad que impera en nuestro derecho como un derecho fundamental de las personas (ningún ser humano puede ser discriminado por razón de sexo), muchas de las imágenes que se emiten suelen ser estereotipadas e inexactas y negativas, describiendo a las mujeres más por su apariencia que por sus capacidades.

Mantener los discursos estereotipados en la publicidad comporta que se siga amparando patriarcados de consentimiento, asignando roles de género a ambos sexos. Los estereotipos de género que se observan a través del discurso de la publicidad, hacen referencia especialmente a la invisibilización y ridiculización de la mujer, a su rol de víctima, a la subyugación de las mujeres con patrones estéticos, al reforzamiento de roles tradicionales que minimizan el universo femenino a un ámbito privado-doméstico, a la cosmovisión masculina como modelo a seguir por las mujeres, a la representación de la mujer como persona-objeto en los medios y la especialización temática en función de los géneros. Así, cabe señalar que la distancia entre realidad y contenidos mediáticos se identifica y se argumenta como un hecho de facto en nuestra sociedad que comporta la pérdida de la función constructiva de los medios de comunicación (García-Muñoz y Martínez, 2009). A través de las leyes de género y de los organismos que velan por su cumplimiento se pretende actuar contra este tipo de publicidad que refuerza estereotipos sexistas y discriminatorios, no acorde con el pensamiento y cultura de la sociedad actual.

Para erradicar la desigualdad de género en la publicidad, se requiere implicación social que intervenga en los factores que injieren en esta situación discriminatoria, como son las cuestiones psicológicas, relativas a la construcción social de las identidades sexuadas; las sociológicas, según los roles que se distribuyen en función de los sexos y las políticas vinculadas a las relaciones de poder entre los géneros. En este sentido, se ha desarrollado abundante legislación que recoge medidas protectoras en esta materia.

Es cierto que en el panorama legislativo español, se han promulgado en la última década dos normas que han supuesto un paso importantísimo en la batalla por la igualdad de género, la LOVG de 2004 y la LOI de 2007. Se trata de dos leyes que de manera, integral y multidisciplinar, luchan por la conquista de la igualdad y el respeto a la dignidad humana y la libertad de las personas. Las leyes de igualdad surgen por la necesidad de hacer efectivo el principio de igualdad entre mujeres y hombres y representan una medida legislativa de gran alcance. Nacen con la pretensión de reconocer que los hombres y las mujeres son iguales en dignidad humana y tienen los mismos derechos y, por tanto, deben ejercerlos en condiciones de paridad. Por ello articulan una serie de políticas y medidas, algunas de carácter obligatorio y otras de carácter promocional, pero con la intención última de garantizar la igualdad de mujeres y hombres (Ventura, 2010). 
Ambas normas han integrando este derecho, como un principio jurídico universal, reconocido en diversos textos comunitarios e internacionales sobre derechos humanos. Así, la igualdad, deja de ser algo excepcional para convertirse en la regla a aplicar en cualquier caso. La transversalidad, se convierte en el elemento estructural, impregnando espacios y tiempos, para evitar y prevenir las conductas discriminatorias a través de proporcionar respuestas globales a la violencia que se ejerce sobre las mujeres y a través de políticas activas para hacer efectivo el principio de igualdad.

\section{Conclusión}

La publicidad es una vía de transmisión de conceptos, valores y actitudes sociales. También, puede atribuir estereotipos que son absorbidos por los públicos y que son sexistas y discriminatorios con la imagen de la mujer. Los medios de comunicación coadyuvan a la creación de una imagen de mujer estereotipada, cosificada e irreal. En este sentido, pese a que en la actualidad existen instrumentos legales para lograr la igualdad, sin embargo desde los medios de comunicación se potencia la desigualdad, es decir, la publicidad, hoy por hoy, discrimina a la mujer.

Las nuevas tecnologías de la comunicación ofrecen un nuevo universo, lleno de posibilidades y de alcance ilimitado. Sin embargo, no obstante la democratización y de estos nuevos instrumentos, los contenidos que se utilizan suelen ser los mismos, ya que en la mayoría de los casos, los nuevos modelos publicitarios complementan las campañas publicitarias de las marcas, siguiendo el hilo conductor de las mismas, que si es discriminatorio en los modelos tradicionales, continuará siéndolo en los nuevos modelos.

Queda todavía un importante camino por realizar para conseguir que la igualdad de género que promulga nuestro derecho, sea real y efectiva, y en este punto la LOVG 2004 y la LOI 2007, ayudarán a conseguir este objetivo . Pero, es necesario que la aplicación de estas normas sea real y efectiva, para poder pasar de un estadio de igualdad formal a una situación de igualdad real. Por ello se deben arbitrar medidas para impedir las estereotipaciones, $\mathrm{y}$ adoptar disposiciones como la utilización de un lenguaje genérico que visibilice a la mujer.

Llegados a este punto, la única solución para lograr que la imagen de la mujer en la publicidad se adecué a su verdadero papel en la sociedad actual radica en un profundo cambio de valores y actitudes sociales, que se implique con las leyes de género. No olvidemos que la publicidad verdaderamente sólo discrimina por consumo y por este motivo, los/as anunciantes serán sensibles a los cambios e intereses que la ciudadanía les demande, por lo que dependerá del requerimiento de la sociedad el tener una publicidad más igualitaria y menos sexista.

\section{Referencias bibliográficas}

AYMERICH FRANCH, Laura (2007): "Nous formats publicitaris en televisió interactiva.. Bellaterra". Treball d'Investigació. Direcció: Emili Prado Picó i Matilde Delgado Reina [Enlace on line: http://www.griss.org/curriculums/aymerich/tr_lauraymerich.pdf] 
BERNAD, Estela (2010): "Ilicitud de las representaciones degradantes y humillantes del cuerpo femenino en la publicidad: Especial referencia a la anorexia". En Icono 14. [http://www.icono14.net/A8/ESP.-Comunicacion-y-Sociedad/ilicitud-de-las-representaciones]

CALDEVILLA DOMÍNGUEZ, David (2010): "Mujeres 2.0. Una visión sobre el consumo de Internet de la mujer de hoy". En Icono 14, no 15 ["Mujeres 2.0. Una visión sobre el consumo de Internet de la mujer de hoy"]

COBO, Rosa (1995): "Género", en AMORÓS, Celia (directora): Diez palabras clave sobre mujer. Pamplona, Edit Verbo Divino, pp. 55-84.

GARCÍA-MUÑOZ, Nùria y MARTÍNEZ, Luisa (2009): «El consumo femenino de la imagen de la mujer en la publicidad. El sexismo en las campañas publicitarias rechazadas por la audiencia» en Trípodos, $\mathrm{n}^{\circ} 24$, Barcelona, Facultat de Comunicació Blanquerna, p.149-160 .

OBSERVATORIO DE LA IMAGEN DE LAS MUJERES: Informes 2000, 2001, 2002, 2003, 2004, 2005, 2006, 2007. Instituto de la Mujer. Ministerio de Trabajo y Asuntos Sociales. [http://www.mtas.es/mujeres]

SALES CIGES, María Auxiliadora (2010): "Las mujeres en la sociedad de la información". En VV.AA: Igualdad de género en el ámbito público y privado. Castellón, Universitat Jaume I Fundación Isonomía, pp 214-230.

VENTURA FRANCH, Asunción (2010): "Las Leyes de igualdad entre mujeres y hombres". En VV.AA.: Igualdad de género en el ámbito público y privado. Castellón, Universitat Jaume I, Fundación Isonomía, pp. 337-354.

VINYALS, Manel; ECHAZARRETA, Carmen; y MARTÍN-CASADO, Teresa Gema (2011): "Nuevas estrategias en la promoción de las marcas de moda en Internet", en Nuevas Tendencias e hibridaciones de los discursos audiovisuales en la cultura digital contemporánea. Actas del IV Congreso Internacional sobre análisis filmico. Universitat Jaume I, Castellón 4-6 mayo de 2011. Madrid, Ediciones de Ciencias

\section{Estela BERNAD MONFERRER}

Profesora contratada doctora, Departamento de Ciencias de la Comunicación

Facultad de Ciencias Humanas y Sociales

Universitat Jaume I de Castelló

Avda. Sos Baynat, $\mathrm{s} / \mathrm{n}$

12070 Castellón de la Plana

bernad@uji.es 